\title{
Effect of tall instrumented towers on the statistical distributions of lightning current parameters and its influence on the power system lightning performance assessment
}

\author{
A. Borghetti, C.A. Nucci, M. Paolone
}

\begin{abstract}
Statistical distributions of lightning current amplitude, time-to-peak value and other lightning current parameters, used in power system insulation coordination, are based on experimental data obtained by means of tall instrumented towers. It is, however, generally accepted that these distributions are affected by the presence of the tower due to its attractive radius. Current amplitudes, in particular, are biased towards higher values with respect to those that would refer to flashes at ground. In this paper we propose a procedure, based on the Monte Carlo method, that allows to infer the statistical distributions of lightning current parameters at ground level starting from the 'classical' ones, i.e. those obtained from data measured using tall instrumented towers. The procedure is more general than others proposed in the literature for the same purpose, in that it can be applied whatever attractive radius expression is used. The procedure is applied to quantify the tower bias on the classical statistical distribution of lightning current amplitude for a number of available attractive radius expressions. Additionally, the comparison between the indirect-lightning performances of an overhead line, inferred by adopting both the classical, toweraffected, and the unaffected statistical distributions at ground of the lightning current amplitude, is given.
\end{abstract}

Index Terms-Power system lightning protection, Lightning statistics, Monte Carlo method, Induced overvoltages.

\section{NOMENCLATURE}

Let $\mathrm{X}$ be a random variable with lognormal distribution; $\mu$ denotes the median value of $X$, which corresponds to the antilogarithm of the mean value of variable $\log (\mathrm{X}) ; \delta$ denotes the standard deviation of variable $\log (\mathrm{X}) . \delta$ values are given with reference to common logarithm, i.e., base 10 .

\section{INTRODUCTION}

$\mathrm{T}$ he probabilistic approach to power system insulation coordination requires the knowledge of the statistical distributions of lightning current parameters [1]. Nowadays, the distributions adopted by power engineers are basically those derived from the experimental data gathered by means of ele-

A. Borghetti, C. A. Nucci and M. Paolone are with the Department of Electrical Engineering, University of Bologna, 40136 Bologna, Italy. (e-mail: \{alberto.borghetti, carloalberto.nucci, mario.paolone\} (a)mail.ing.unibo.it). vated instrumented towers in the last decades [2-7]. We shall refer to these distributions as to the 'conventional' ones. There is, however, general concern on the fact that these distributions are affected by the presence of the tower; lightning current amplitudes, in particular, are 'biased' towards higher values [8-13], as the so-called attractive radius of the tower tends to increase for flashes with larger currents ${ }^{1}$. There are indeed several expressions for such an attractive radius [15-20], all predicting its increase with the return-stroke current.

In view of the above, the conventional distributions should not be used as such for power system insulation coordination studies. One should first eliminate the early-mentioned tower effect to obtain distributions at ground, and then apply the obtained distributions to the specific structure of interest (line poles, line conductors) by taking into account the relevant direct-stroke exposure model (given, in turns, by the attractive radius - or lateral distance - expression). Note, additionally, that for the case of overhead distribution lines, for which it is very important to take into account the overvoltages induced by strokes hitting the ground in their vicinity (indirect strokes), to accomplish appropriate insulation coordination the statistical distributions of interest are indeed those of the lightning current parameters at ground.

Pettersson [11] already studied the problem and proposed an analytical formula that allows obtaining the statistical distribution of the lightning current amplitude at ground starting from that obtained from elevated instrumented towers. Such a formula, which applies only when the relationship between the attractive radius and the current amplitude is exponential, and only to the current amplitude, has been afterwards applied by Sabot [12] to the Cigré lightning current amplitude distribution. In [44], Rizk has presented the relationship among the probability density functions of peak currents relevant to strokes hitting a mast, of strokes hitting a conductor, and of strokes to open ground. These relationships have been applied in [44] by Rizk to the IEEE lightning current distribution [6], having a median value of $31 \mathrm{kA}$ (and assumed to be inferred only from transmission line

\footnotetext{
${ }^{1}$ The lightning current parameters are also affected by the influence of the reflections at the top and at the basis of the tower (e.g. [14]). These effects are here disregarded. Also, in this paper, we focus only on downward negative
} flashes. 
measurements), to obtain a median value for open ground equal to $23 \mathrm{kA}$. To perform this calculation the lateral distance expression proposed in [18] was applied, which is of the same exponential type assumed by Pettersson in order to derive its formula.

In order to overcome the above-mentioned limits of the Pettersson formula, and to allow for the treatment of additional lightning current parameters different from the peak amplitude, we propose here an alternative approach based on the Monte Carlo method. With it, it is possible to infer the statistical distributions of any lightning current parameter at ground starting from the 'conventional' ones, for any of the exposure models proposed in the literature. Using the proposed approach, we infer a number of statistical distributions of various lightning current parameters, and this for different attractive radius expressions. We eventually evaluate the impact of the above-mentioned tower effect on the assessment of the lightning performance of distribution overhead lines.

The different models describing the exposure of a tower and/or an overhead line to direct lightning strokes are briefly summarized in Section III where various expressions for the attractive radius (lateral distance) are summarized and reviewed. The method that we propose is described in Section IV and, in Section V, is applied to the lightning current parameter distributions of current amplitude and front duration presented in [4], obtained from the experimental records at Monte San Salvatore [21]. Section VI contains a comparison between the indirect-lightning performance of an overhead line inferred by adopting both the affected and the unaffected current statistical distributions.

\section{MODELS DESCRIBING THE EXPOSURE OF AN ELEVATED STRUCTURES TO DIRECT LIGHTNING STROKES}

As the lightning leader descends toward an elevated object, it reaches a point known as the striking point. At this point, it will initiate a juncture either with the object or with the ground depending on its charge, its distance from the structure, on the type (vertical mast or horizontal conductor), and height of the structure. By assuming the leader channel perpendicular to the ground plane, it is generally accepted that the flash will stroke the structure if its prospective ground termination point, i.e. its stroke location in absence of the structure, lies within the so-called "attractive radius" $r_{l}$ (also called "lateral distance" for the case of horizontal conductors, as those of overhead lines).

Several expressions are available to evaluate such a distance. Some of them are based on the Electrogeometric model [22]; as shown in Fig. 1, the value $r_{l}$ (in $\mathrm{m}$ ) is determined from

$$
\begin{array}{ll}
r_{l}=\sqrt{r_{s}^{2}-\left(r_{g}-h\right)^{2}} & \text { for } h<r_{g} \\
r_{l}=r_{s} & \text { for } h \geq r_{g}
\end{array}
$$

where $h$ is the height of the structure (in $\mathrm{m}$ ) and $r_{s}$ and $r_{g}$ are the so-called critical distances (in $\mathrm{m}$ ) to the structure and to the ground respectively. These striking distances are related to the lightning current by means of the following expressions

$$
r_{s}=\alpha \cdot I_{p}^{\beta} \quad r_{g}=k \cdot r_{s}
$$

where $I_{p}$ is the current amplitude in $\mathrm{kA}$, and the values of $\alpha, \beta$ and $k$ are independent of $I_{p}$. Table I reports some of the values proposed in the literature on transmission line shielding. Expression 2 is an approximation of the formula proposed by Love [16] using the exponential format [6].
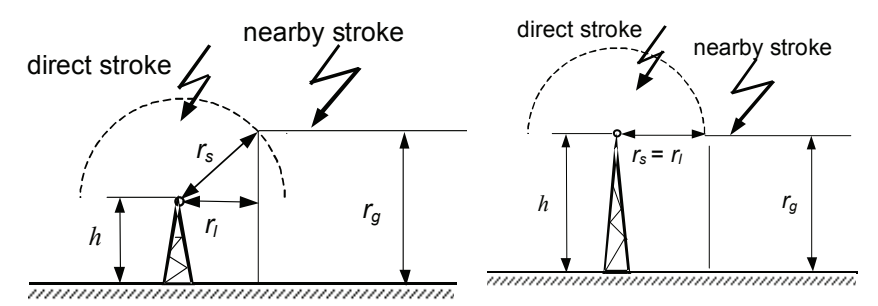

Fig. 1. Electrogeometric model: $r_{s}$ and $r_{g}$ are the striking distances to the structure (mast or horizontal conductor) and to ground respectively; $r_{l}$ is the attractive radius (or lateral distance) of the structure.

TABLE I

VALUES OF CONSTANTS OF STRIKING DISTANCE EQUATIONS (2) PROPOSED BY DIFFERENT AUTHORS

\begin{tabular}{|l|c|c|c|}
\hline \multicolumn{1}{|c|}{ Exposure model } & $\alpha$ & $\beta$ & $k$ \\
\hline 1. Armstrong and Whitehead [15] & 6.7 & 0.80 & 0.9 \\
\hline 2. IEEE [6,16] & 10 & 0.65 & $\begin{array}{c}0.55^{*} \\
0.9^{* *}\end{array}$ \\
\hline
\end{tabular}

* adopted by IEEE Std. 1243 [22] for an average conductor height greater than $40 \mathrm{~m}$.

** adopted by IEEE Std. 1410 [23] for distribution lines

Other expressions, namely those by Eriksson [17], Rizk [18], Dellera and Garbagnati [19,20] are available; they have been inferred more recently by regression analysis, from the results of more complex and physically oriented models than the Electrogeometric one. For these expressions, a formula of the following type can be used for the attractive radius

$$
r_{l}=c+a \cdot I_{p}^{b}
$$

where the values of $a, b$ and $c$ depend on the specific expression, and are shown in Table II.

TABLE II

VALUES OF CONSTANTS OF ATTRACTIVE RADIUS AND LATERAL DISTANCE EQUATION (3) PROPOSED BY DIFFERENT AUTHORS

\begin{tabular}{|l|c|c|c|}
\hline \multicolumn{1}{|c|}{ Exposure model } & $c$ & $A$ & $b$ \\
\hline 3. Eriksson [17] & 0 & $\begin{array}{c}0.84 \mathrm{~h}^{0.6 *} \\
0.67 \mathrm{~h}^{0.6 * *}\end{array}$ & $0.7 \mathrm{~h}^{0.02}$ \\
\hline 4. From Rizk [18] & 0 & $\begin{array}{c}2.83 \mathrm{~h}^{0.4 *} \\
1.57 \mathrm{~h}^{0.45 * *}\end{array}$ & $\begin{array}{c}0.63^{*} \\
0.69 * *\end{array}$ \\
\hline $\begin{array}{l}\text { 5. From Dellera and Garbagnati } \\
\text { [19,20] }\end{array}$ & $3 \mathrm{~h}^{0.6}$ & $0.028 \mathrm{~h}$ & 1 \\
\hline
\end{tabular}

* for towers

** for horizontal conductors.

It is worth noting that concerning the Eriksson expression, henceforth called expression 3, in [17] two lateral distance formulas are proposed, one for masts with heights up to $100 \mathrm{~m}$, and another one for horizontal conductors, with an $80 \%$ reduction of parameter $a$ (see Table II).

Concerning the Rizk expression (expression 4), in [18] an analytical formula is proposed for horizontal conductors with 
height range of $10 \mathrm{~m}$ and $50 \mathrm{~m}$ and for lightning currents with $I_{p}$ in the range 5-31 kA. The parameters are those of Table II. For free standing structures, in [18] the two following formulas are given:

$$
\begin{array}{ll}
r_{l}=24.6 \cdot h^{0.40} & \text { for } I_{p}=31 \mathrm{kA} \text { and } h \text { in the range } 10-60 \mathrm{~m}, \\
r_{l}=12.4 \cdot I^{0.63} & \text { for } \mathrm{h}=40 \mathrm{~m} \text { and } I_{p} \text { in the range of } 5-60 \mathrm{kA} .
\end{array}
$$

From these two formulas, a first approximation for coefficient $a$ of Table II is derived by dividing 24.6 by $31^{0.63}$, then obtaining, for different tower heights, curves similar to those shown in Fig. 5 of [18].

Concerning expression 5, the constant values have been inferred in [25] by interpolation of plots of the lateral distance of a slim structure vs. its height (in the range 5 to $100 \mathrm{~m}$ ), calculated using the leader progression model of DelleraGarbagnati $[19,20]$.

\section{PROCEDURE FOR THE EVALUATION OF LIGHTNING CURRENT DISTRIBUTIONS TO GROUND}

To obtain the statistical distributions of lightning parameters at ground one should be able to record the lightning currents of a large number of lightning flashes hitting the ground within a certain area. However, to accomplish that, one needs the presence of a tall instrumented tower, which, as earlier mentioned, does affect the distributions. As a matter of fact, of all the strokes that, in absence of the tower, would hit the ground in its vicinity, the tower attracts only some of them, due to the already described attractive radius concept. However, if we consider an area around the tower location, supposed circular for convenience, such that its radius is equal to the attractive radius $r_{l}^{*}$ corresponding to the minimum peak current value $I_{p}{ }^{*}$ observed at the top of the tower, all the strokes with perspective stroke location within such an area will be collected by the tower.

The proposed approach consists of applying the Monte Carlo method to generate a population of lightning events with perspective stroke location within such an area of radius $r_{l}{ }^{*}$, starting from the conventional statistical distributions of the lightning currents collected by the tower, as described in what follows. We generate a significant number of lightning events (e.g. $10^{6}$ ), each characterized by a number of random variables (amplitude $I_{p}$, time to peak value $t_{f}$, etc.), and perspective radial distance $x_{g}$ from the tower location. For each event, the values of the various lightning current parameters are randomly selected from the corresponding statistical distributions relevant to the tower measurements. Correlation coefficients between the lightning parameters can be also taken into account by applying the inverse transform method [26], as shown for instance in [27]. The value of $x_{g}$ associated to each direct lightning event is generated assuming that the stroke locations are uniformly distributed around the tower; for each lightning event, $x_{g}$ is then generated from a distribution with probability density function equal to $2 \cdot x_{g} / r_{l}^{2}$. From the population of direct lightning events generated as above described, we select the set of stroke events having distance $x_{g}$ from the tower location lower than $r_{l}^{*}$. The statistical distributions of the lightning parameters associated to these events are then evaluated, which, under the considered assumptions, are indeed the desired distributions of the lightning parameters to open ground, without the bias introduced by the tower.

\section{APPLICATION OF THE PROPOSED PROCEDURE TO THE LIGHTNING CURRENT STATISTICAL DISTRIBUTIONS BY BERGER ET AL.}

Let us now consider the statistical distributions of the lightning current parameters by Berger et al. [3], obtained from measurements on the $70 \mathrm{~m}$ high tower installed at the top of Monte San Salvatore in Switzerland (near Lugano, $912 \mathrm{~m}$ above sea level $)^{2}$. In Table III the median $\mu_{t}$ and standard deviation $\delta_{t}$ values of the first peak and of the front duration (assumed to be lognormally distributed) as given in [4] are reported.

TABLE III

MEDIAN AND STANDARD DEVIATIONS OF FIRST PEAK AND FRONT DURATION OF NEGATIVE DOWNWARD FIRST STROKES RECORDED AT MONTE SAN SALVATORE [4]

\begin{tabular}{|c|c|c|}
\hline Parameter & $\mu_{t}$ & $\delta_{t}$ \\
\hline First Peak $I_{p}(\mathrm{kA})$ & 27.7 & 0.20 \\
\hline Front duration $t_{f}(\mu \mathrm{s})$ & 3.8 & 0.24 \\
\hline
\end{tabular}

The median value and standard deviation of parameter $t_{f}$ (front duration) are obtained by those of parameter $T_{30}$, i.e. the time interval between the 30 percent and 90 percent amplitude intercepts $\left(t_{f}=T_{30} / 0.6\right)$ [4]. Also, a correlation coefficient $\rho_{t}=0.47$ is taken into account between peak value and front duration [4].

In Table IV we report the results obtained by applying our procedure to the experimental distributions of Table III for all the models of Tables I and II describing the lightning exposure of the tower. For these calculations, the experimental data of Berger et al. have been assumed to be collected by a tower on a ground plane, assuming that the effect of the presence of the mountain can be disregarded in the expression of the attractive radius of the tower, a point that certainly requires additional investigation $[4,44]$. The minimum value of current peak has been assumed equal to $2 \mathrm{kA}$, for all the calculations.

The distributions at ground of current amplitude have median values ranging from 27.4\% (attractive radius expression 3) to $20.2 \%$ (attractive radius expression 5) lower than the median of the original distribution. The median values of front times range from $15.8 \%$ to $10.5 \%$ lower than the median of the original distribution, due to the correlation between front time values and current amplitudes.

\footnotetext{
${ }^{2}$ For a certain limited period of time, at the top of the mountain there were two towers of different height $(70$ and $90 \mathrm{~m})$. In this paper we disregard the effect of the presence of the second tower on the statistical distributions of the lightning current parameters.
} 
TABLE IV

MEDIAN AND STANDARD DEVIATIONS OF CURRENT PARAMETER DISTRIBUTIONS TO GROUND FOR THE ATTRACTIVE RADIUS EXPRESSIONS OF TABLES I AND II.

\begin{tabular}{|c|l|c|c|c|c|c|}
\hline \multicolumn{2}{|c|}{ Parameter } & \multicolumn{5}{c|}{ Exposure model } \\
\cline { 2 - 7 } & 1 & 2 & 3 & 4 & 5 \\
\hline \multirow{2}{*}{ Peak $I_{p}(\mathrm{kA})$} & $\mu_{g}$ & 20.2 & 21.1 & 20.1 & 21.3 & 22.1 \\
\cline { 2 - 7 } & $\sigma_{g}$ & 0.21 & 0.20 & 0.20 & 0.20 & 0.19 \\
\hline \multirow{2}{*}{$\begin{array}{c}\text { Front } \\
\text { duration } \\
(\mu \mathrm{s})\end{array}$} & $\mu_{f}$ & 3.2 & 3.3 & 3.2 & 3.3 & 3.4 \\
\cline { 2 - 7 } & $\sigma_{g}$ & 0.24 & 0.24 & 0.24 & 0.24 & 0.24 \\
\cline { 2 - 7 } & $\rho_{g}$ & 0.49 & 0.47 & 0.48 & 0.47 & 0.45 \\
\hline
\end{tabular}

We now compare the results obtained with the proposed procedure with those that can be obtained by using the earlier-mentioned analytical formula derived by Pettersson [11]. Such a formula allows calculating the $\mu_{g}$ and $\sigma_{g}$ values of the lognormal distribution of the current amplitudes at ground, from the corresponding $\mu_{t}$ and $\sigma_{t}$ values of the conventional distribution collected by means of an instrumented tower:

$$
\begin{aligned}
& \sigma_{g}=\sigma_{t} \\
& \mu_{g}=\mu_{t} \cdot \exp \left(-2 \cdot b \cdot \sigma_{g}^{2}\right)
\end{aligned}
$$

where $b$ is the exponent of the attractive radius expression assumed by Pettersson to have an exponential form - namely of type (3) with $c=0$ - which means that (4) can be applied to exposure models 3 and 4 . For the case of the Electrogeometric model (models 1 and 2), the attractive radius assumes an exponential form only if $h>r_{g}$ (equation (1b)) or [28] when both $r_{g}=r_{s}$ and $h<<r_{g}{ }^{3}$. In this second case, the attractive radius can be written as

$$
r_{l}=\sqrt{2 \cdot \alpha} \cdot h^{0.5} \cdot I_{p}^{\beta / 2}
$$

To the best of our knowledge, equation (4) cannot be applied to exposure model 5.

Following [12] we have applied (4) to the current peak distributions by Berger et al. [3], by assuming the values of parameter $b$ of (4) equal to the $b$ values reported in Table II for exposure models 3 and 4 . For exposure models 1 and 2 (electrogeometrical) we have applied (4) by using for coefficient $b$ both $\beta$ and $\beta / 2$. We have also applied equation (4) to exposure model 5 , in order to quantify the effect of parameter $c$, not taken into account in (4), on the results. The median values $\mu_{g}$ of Table $\mathrm{V}$ are then obtained. (Note, as earlier mentioned, that by using (4), only the parameters of the statistical distribution of lightning current amplitudes can be evaluated.)

The comparison of the results of Table IV and V shows that the proposed procedure gives practically the same results as those obtained by applying (4), when exposure models 3 and 4 are applied, which are indeed of the type assumed by Pettersson in order to derive (4). For exposure model 2, the median value predicted by (4) matches with that of the proposed approach if $b$ is assumed equal to $\beta$; this is supported by the fact that, for model 2 , the probability that $r_{g}$ be larger than $70 \mathrm{~m}$ is greater than $90 \%$. For the case of exposure model

\footnotetext{
${ }^{3}$ At least for most of lightning current amplitudes [12].
}

1 , the result of (4) differs from that of the proposed approach when $b$ is set equal to $\beta / 2$; in fact the probability that $r_{g}$ be much lower than $70 \mathrm{~m}$ is very low (our calculations show that the probability that $r_{g}$ be lower than $70 / 3$ is only $0.02 \%$ ). For this model, however, the result predicted by (4) slightly differs form our result even for $b=\beta$, as, for this case, the probability that $r_{g}$ be larger than $70 \mathrm{~m}$ is only $28.8 \%$.

\section{TABLE V}

MEDIAN AND STANDARD DEVIATIONS OF CURRENT AMPLITUDE DISTRIBUTION TO GROUND BY APPLYING EQ. (4) FOR THE DIFFERENT ATTRACTIVE RADIUS EXPRESSIONS (EXPOSURE MODELS) OF TABLES I AND II.

\begin{tabular}{|c|c|c|c|c|c|c|c|c|}
\hline \multicolumn{2}{|c|}{ Parameter } & \multicolumn{7}{|c|}{ Exposure model } \\
\cline { 2 - 8 } \multicolumn{2}{|c|}{} & \multicolumn{2}{|c|}{1} & \multicolumn{2}{|c|}{2} & 3 & 4 & 5 \\
\hline $\begin{array}{c}\text { Peak } \\
I_{p}(\mathrm{kA})\end{array}$ & $\mu_{g}$ & $23.4 *$ & $\begin{array}{c}19.7^{*} \\
*\end{array}$ & $24.1^{*}$ & $\begin{array}{c}21.0^{*} \\
*\end{array}$ & 20.0 & 21.2 & 18.1 \\
\cline { 2 - 8 } & 0.20 & 0.20 & 0.20 & 0.20 & 0.20 & 0.20 & 0.20 \\
\hline
\end{tabular}

* from (4) using $b=\beta / 2\left(r_{g}=r_{s}\right.$ and $\left.h<<r_{g}\right)$

** from (4) using $b=\beta\left(h>r_{g}\right)$

\section{APPLICATION OF THE RESULTS TO THE EV ALUATION OF INDIRECT LIGHTNING PERFORMANCE OF OVERHEAD LINES}

To evaluate the impact of the proposed modification of the statistical distributions of lightning current parameters at ground, in this paragraph the indirect lightning performance of an overhead line is calculated by using both the lighting current statistical parameters of Table III, affected by the presence of the tower, and those, corrected according to the proposed procedure, of Table IV.

To this purpose, we consider a $2 \mathrm{~km}$ long, $10 \mathrm{~m}$ high overhead line, matched at both end, and a "striking area" around the line, wide enough to include all the lightning events that can induce a voltage along the line with maximum amplitude greater than the considered insulation level (e.g. about $20 \mathrm{~km}^{2}$ ). The procedure presented by the authors in [27], also based on the Monte Carlo method, is applied to generate a significant number of events (al least $10^{4}$ ). Each event is characterised by four random variables: the peak value of the lightning current $I_{\mathrm{p}}$, its front time $t_{\mathrm{f}}$ (correlated) and the two co-ordinates of the stroke location. Such events are generated, as above mentioned, assuming the statistical lognormal distributions of current peak and front time of both Table III and Table IV; the stroke locations are uniformly distributed within the earlier mentioned surface around the line (see $[25,27]$ for further details). As we are calculating the indirect lightning performance of the line, all the events corresponding to direct strokes are disregarded.

For each event the lightning-induced voltages on the line are calculated by means the LIOV code [29-31]. ${ }^{4}$

\footnotetext{
${ }^{4}$ The LIOV code has been developed in the framework of an international collaboration involving the University of Bologna (Department of Electrical Engineering), the Swiss Federal Institute of Technology (Power Systems Laboratory), and the University of Rome "La Sapienza" (Department of Electrical Engineering). It is based on the field-to-transmission line coupling formulation of Agrawal et al. [32], suitably adapted for the case of an overhead line above a lossy ground illuminated by an indirect lightning electromagnetic field; the LEMP is calculated by assuming the MTLE returnstroke engineering model $[33,34]$ and using the Cooray-Rubinstein formula $[35,36]$ to take into account the finite value of the ground resistivity in the
} 
The lightning performance of the line is calculated by using the different lateral distance expressions of Tables I and II, relevant to distribution lines, in order to distinguish between direct and indirect strokes. The results obtained by using the parameters of Table III are shown in Figs. 2 and 4 and those obtained by using the parameters of Table IV are shown in Figs. 3 and 5. Results of Figs. 2 and 3 refer to the case of perfectly conducting ground plane, while those of Figs. 4 and 5 refer to the case of a ground with conductivity equal to $0.001 \mathrm{~S} / \mathrm{m}$. It can be observed that the application of the modified current statistical distributions results, as expected, in a better performance of the distribution line to indirect lightning strokes, being these distributions characterized by a lower median value. Additionally, it is shown that the results differ very much depending on the expression adopted to evaluate the lateral distance.

\section{CONCLUSIONS}

In this paper we have proposed a procedure, based on the Monte Carlo method, that allows to infer the statistical distributions of lightning current parameters (peak amplitude, front time, etc.) at ground level, starting from those obtained from measurements using tall instrumented towers. The procedure is more general than others proposed in the literature for the same purpose, in that it can be applied whatever attractive radius (lateral distance) expression is assumed, and is not limited to the current peak amplitude only. The distribution of the peak amplitude at ground exhibits median values ranging from $27.4 \%$ (attractive radius expression by Eriksson) to $20.2 \%$ (attractive radius by DelleraGarbagnati) lower than the median of the original distribution. Other exposure models (IEEE, Amstrong-Withehead and Rizk) predict median values that are within the abovementioned range. The median values of current front times range from $15.8 \%$ to $10.5 \%$ lower than the median of the original distribution, as a consequence of the generally assumed correlation between front time values and current amplitudes.

We have also compared the indirect-lightning performance of an overhead distribution line inferred by adopting both the affected and the unaffected current amplitude statistical distributions, and have found a difference in the two cases. The performance of the line appears, however, more affected by the exposure model that is used for the determination of indirect strokes. Such a difference tends to decrease for increasing values of the ground resistivity.

The authors feel that the above conclusions should be taken into account in power systems insulation coordination practice.

field calculation with correction by Cooray [37] according to the remarks by Wait [38]. Concerning the effect of the ground resistivity in the calculation of the line parameters, with particular reference to the ground transient resistance, the Carson expression [39] is used. Indeed, as in the LIOV code all above-mentioned models are implemented in the time domain, the ground transient resistance formula derived by Timotin [40] which corresponds to the Carson formula is used. Recently, the expression proposed in [41] has been introduced in the LIOV code, which corresponds to the general Sunde's expression for the ground impedance [42].

\section{ACKNOWLEDGEMENTS}

The authors gratefully acknowledge Dr. A. Sabot whose helpful suggestions have motivated this paper, and Dr. F. Rachidi for his useful comments.

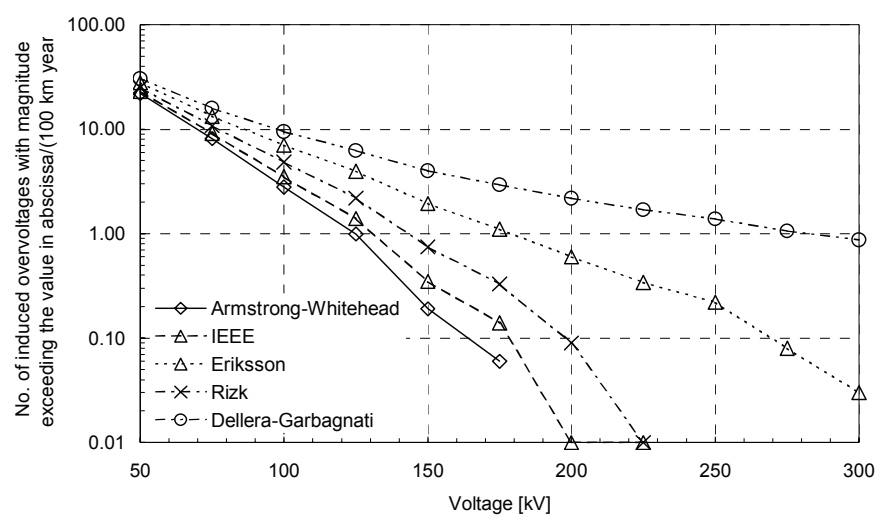

Fig. 2. Indirect-lightning performances of an overheard line above a perfectly conducting ground, by adopting the different lateral distance expression of Tables I and II and the lightning current distributions of Table III as distributions at ground.

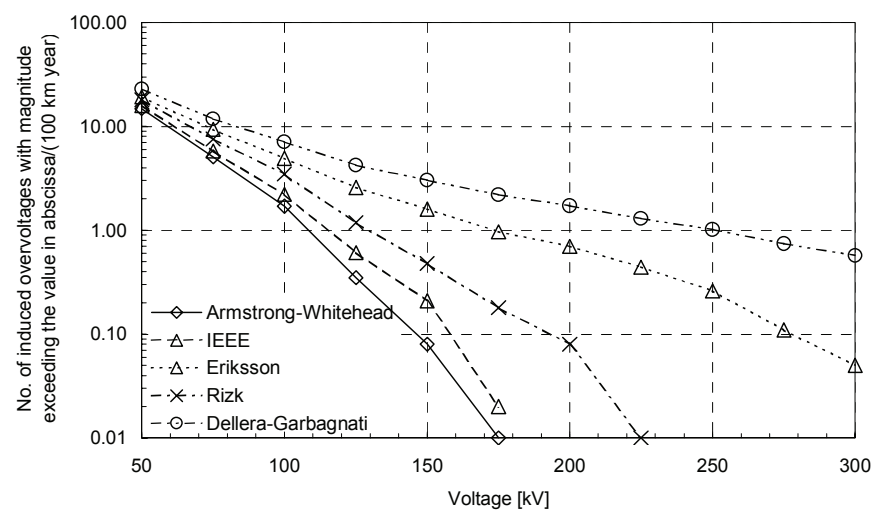

Fig. 3. Indirect-lightning performances of an overheard line above a perfectly conducting ground, by adopting the different lateral distance expression of Tables I and II and the relevant current statistical distributions at ground of Table IV.

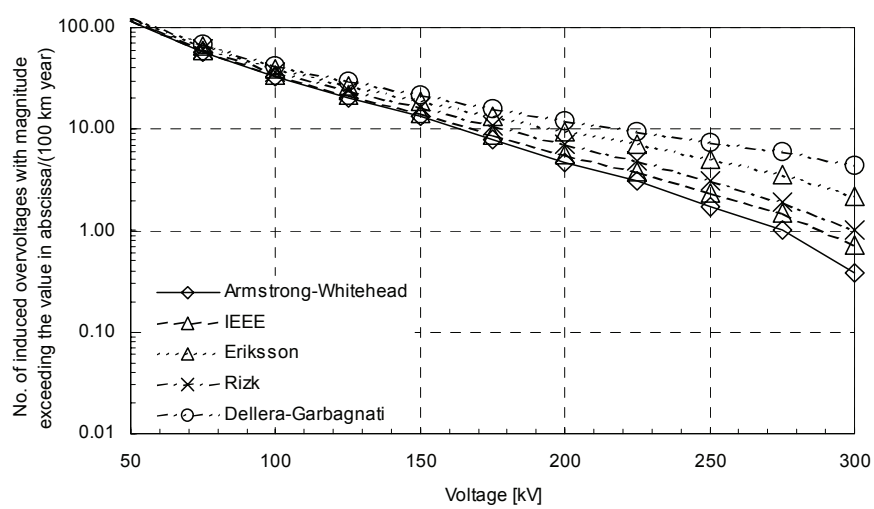

Fig. 4. Indirect-lightning performances of an overheard line above a lossy ground with conductivity equal to $0.001 \mathrm{~S} / \mathrm{m}$, by adopting the different lateral distance expression of Tables I and II and the lightning current distributions of Table III as distributions at ground. 


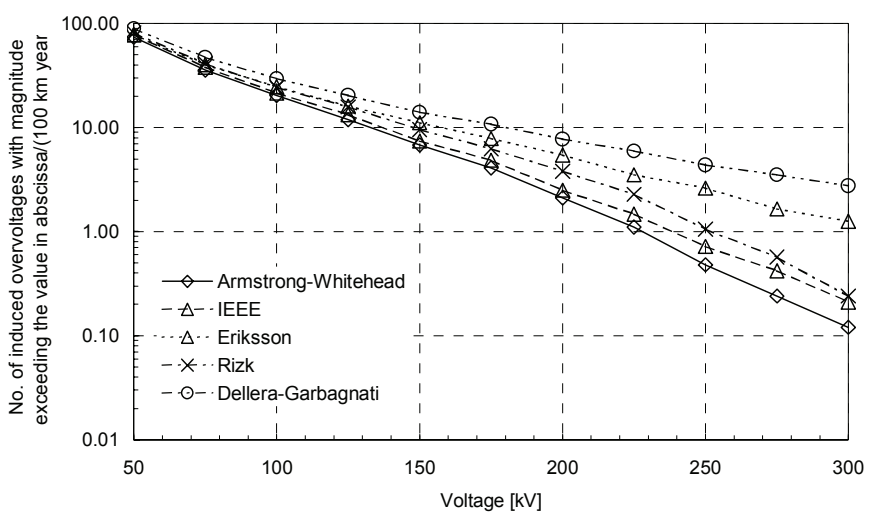

Fig. 5. Indirect-lightning performances of an overheard line above a lossy ground with conductivity equal to $0.001 \mathrm{~S} / \mathrm{m}$, by adopting the different latera distance expression of Tables I and II and the relevant current statistica distributions at ground of Table IV.

\section{REFERENCES}

[1] L. O. Barthold and L. Paris, "The probabilistic approach to insulation coordination", Electra, no. 13, pp. 41-58, 1970

2] F. Popolansky, "Frequency distribution of amplitudes of lightning currents", Electra, no. 22, 1972.

[3] K. Berger, R. B. Anderson and H. Kroninger, "Parameters of Lightning Flashes", Electra, no. 41, pp. 23-37, July 1975.

[4] R. B. Anderson and A.J. Eriksson, "Lightning Parameters for Engineering Applications", Electra, no. 69, pp. 65-102, March 1980.

[5] R.B. Anderson and A.J. Eriksson, "A Summary of Lightning Parameter for Engineering Applications", in Proc. of CIGRE, paper no. 33-06, 1980.

[6] J. G. Anderson, "Lightning performance of EHV-UHV lines", in Transmission line reference book, $345 \mathrm{kV}$ and above, Palo Alto: EPRI, 1982.

[7] E. Garbagnati and G. B. Lopiparo, "Lightning Parameters - Results of 10 Years of Systematic Investigation in Italy", in Proc. International Aerospace Conference on Lightning and Static Electricity, Oxford, AL pp. A1-1 to A1-12, 1982.

[8] M.A. Sargent, "The Frequency Distribution of Current Magnitudes of Lightning Strokes to Tall Structures", IEEE Trans. Power Apparatus and Systems, PAS-91(5), pp. 2224-2229, September/October 1972.

[9] R. Golde, "The lightning conductor", in Lightning: Volume 2, Lightning protection, R. Golde, Ed., New York: Academic Press, pp. 545 -573, 1977.

[10] A.M. Mousa, K.D. Srivastava, "The implications of the electrogeometric model regarding effect of height of structure on the median amplitude of collected lightning strokes", IEEE Trans. Power Delivery, vol. 4, no. 2, pp. $1450-1460,1989$.

[11] P. Pettersson, "A unified probabilistic theory of the incidence of direct and indirect lightning strikes", IEEE Trans. Power Delivery, vol. 6 , no. 3, pp. $1301-1310$, July 1991

[12] A. Sabot, "An engineering review on lightning, transient overvoltages and the associated elements of electrogeometric compatibility", in Proc. Ninth International Symposium on High Voltage Engineering, Graz, Austria, 1995.

[13] G. Diendorfer, W. Schulz, "Lightning incidence to elevated objects on mountains", in Proc. International Conference on Lightning Protection, Birmingham, UK, 1998.

[14] S. Guerrieri, C.A. Nucci, F. Rachidi, M. Rubinstein, "On the influence of elevated strike objects on directly measured and indirectly estimated lightning currents", IEEE Trans. Power Delivery, vol. 13, no. 4, pp. $1543-1555,1998$.

[15] H.R. Amstrong and E.R. Whitehead, 'Field and Analytical Studies of Transmission Lines Shielding', IEEE Trans. Power Apparatus and Systems, PAS-87, pp.270-281, January 1968.

[16] E.R. Love, "Improvements on lightning stroke modeling and applications to the design of EHV and UHV transmission lines", M.Sc. Thesis, University of Colorado, 1973.

[17] A.J. Eriksson, "An improved electrogeometric model for transmission line shielding analysis", IEEE Trans. Power Delivery, vol. 2, pp. 871886 , July 1987

[18] F.A.M. Rizk, 'Modelling of Transmission Line Exposure to Direct Lightning Strokes', IEEE Trans. Power Delivery, vol. 5, no.4, pp. 1983-1997, October 1990.
[19] L. Dellera, E. Garbagnati, "Lightning stroke simulation by means of the leader progression model, Parts I and II", IEEE Trans. Power Delivery, vol. 5, no. 4, pp. 2009-2029, October 1990.

[20] M. Bernardi, L. Dellera, E. Garbagnati, G. Sartorio, "Leader progression model of lightning: updating of the model on the basis of recent test results", in Proc. International Conference on Lightning Protection, Florence, pp. 399-407, 1996

[21] K. Berger, "Novel observations of lightning discharges: Results of research on Mount San Salvatore", Jour. Franklin Institute, 283, 1967.

[22] R.H. Golde, "The Frequency of occurrence and the distribution of lightning flashes to transmission lines", AIEE Trans., 64, pp. 902-910, 1945.

[23] IEEE Guide for Improving the lightning performance of electric power overhead distribution lines, IEEE Standard 1410-1997, June 1997.

[24] IEEE Guide for Improving the lightning performance of transmission lines, IEEE Standard 1243-1997, Dec. 1997.

[25] A. Borghetti, C.A. Nucci, M. Paolone, M. Bernardi, "Effect of the lateral distance expression and of the presence of shielding wires on the evaluation of the number of lightning induced voltages", in Proc. 25th International Conference on Lightning Protection, Rhodes, Greece, September 2000.

[26] R.Y. Rubinstein, Simulation and the Monte Carlo method, New York, Wiley, 1981.

[27] A. Borghetti, C.A. Nucci, "Estimation of the frequency distribution of lightning induced voltages on an overhead line above a lossy ground: a sensitivity analysis", in Proc. International Conference on Lightning Protection, Birmingham, UK, September 1998.

[28] P. Pettersson, "Probabilistic theory of lightning incidence", in Proc. $22^{\text {nd }}$ International Conference on Lightning Protection, Budapest, UK, September 1994

[29] C.A. Nucci, F. Rachidi, M. Ianoz and C. Mazzetti, "Lightning-induced voltages on overhead power lines", IEEE Trans. on EMC, vol. 35, 1993.

[30] F. Rachidi, C.A. Nucci, M. Ianoz and C. Mazzetti, "Influence of a lossy ground on lightning-induced voltages on overhead lines", IEEE Trans. on EMC, vol. 38, No 3, pp. 250-263, 1996.

[31] F. Rachidi, C.A. Nucci, M. Ianoz, "Transient analysis of multiconductor lines above a lossy ground", IEEE Trans. Power Delivery, vol. 14, no. 1, pp. 294-302, 1999.

[32] A.K. Agrawal, Price H.J., Gurbaxani S.H., "Transient response of a multiconductor transmission line excited by a nonuniform electromagnetic field", IEEE Trans. on EMC, vol. 22, no. 2, pp. 119129, May 1980.

[33] C.A.Nucci, C. Mazzetti, F. Rachidi, and M. Ianoz, "On lightning return stroke models for LEMP calculations", in Proc. 19th International Conference on Lightning Protection, Graz, April 1988.

[34] F. Rachidi and C.A. Nucci, "On the Master, Lin, Uman, Standler and the Modified Transmission Line lightning return stroke current models", Journal of Geophysical Research, vol. 95, pp. 20389-20394, Nov. 1990.

[35] V. Cooray, "Horizontal fields generated by return strokes", Radio Science, Vol. 27, No. 4, pp. 529-537, July-August 1992.

[36] M. Rubinstein, "An approximate formula for the calculation of the horizontal electric field from lightning at close, intermediate, and long range", IEEE Trans. on EMC, vol. 38, no. 3, pp. 531-535, August 1996.

[37] V. Cooray, "Some consideration on the 'Cooray-Rubinstein' approximation used in deriving the horizontal electric field over finitely conducting ground", in Proc. 24th International Conference on Lightning Protection, Birmingham, UK, September 1998.

[38] J.R. Wait, "Concerning the horizontal electric field of lightning", IEEE Trans. on EMC, vol. 39, no. 2, pp. 186, May 1997.

[39] J.R. Carson, "Wave propagation in overhead wires with ground return", Bell System Technical Journal, 5, 539-554, 1926.

[40] A.L. Timotin, "Longitudinal transient parameters of a unifilar line with ground return", Rev. Roum. Sci. Techn. Electrotechn. et Energ., 12, 4, pp. 523-535, Bucarest, 1967.

[41] F. Rachidi, S.L. Loyka, C.A. Nucci, M. Ianoz, "On the Singularity of the Ground Transient Resistance of Overhead Transmission Lines", in Proc. 25th International Conference on Lightning Protection, Rhodes, Greece, September 2000.

[42] E.D. Sunde, Earth Conduction Effects in Transmission Systems, New York, Dover, 1968.

[43] A. Borghetti, C.A. Nucci, M. Paolone, "Lightning performances of distribution lines: sensitivity to computational methods and to data", in Proc. IEEE Power Engineering Society Winter Meeting, Columbus, $\mathrm{OH}, 2001$

[44] F.A.M. Rizk, "Modelling of lightning incidence to tall structures", IEEE Trans. Power Delivery, vol. 9, no. 1, pp. 162-193, January 1994. 